\title{
The structural, functional, and molecular organization of the brainstem
}

\section{Rudolf Nieuwenhuys*}

Netherlands Institute for Neuroscience, Amsterdam, Netherlands

\section{Edited by:}

Luis Puelles, Universidad de Murcia, Spain

\section{Reviewed by:}

Jose L. Lanciego, University of

Navarra, Spain

Luis Puelles, Universidad de Murcia,

Spain

Fernando Martinez-Garcia,

Universidad de Valencia, Spain

*Correspondence:

Rudolf Nieuwenhuys, Papehof 25, 1391 BD Abcoude, Netherlands.

e-mail: rudolfn@planet.nl

According to His $(1891,1893)$ the brainstem consists of two longitudinal zones, the dorsal alar plate (sensory in nature) and the ventral basal plate (motor in nature). Johnston and Herrick indicated that both plates can be subdivided into separate somatic and visceral zones, distinguishing somatosensory and viscerosensory zones within the alar plate, and visceromotor and somatomotor zones within the basal plate. To test the validity of this "four-functional-zones" concept, I developed a topological procedure, surveying the spatial relationships of the various cell masses in the brainstem in a single figure. Brainstems of 16 different anamniote species were analyzed, and revealed that the brainstems are clearly divisible into four morphological zones, which correspond largely with the functional zones of Johnston and Herrick. Exceptions include (1) the magnocellular vestibular nucleus situated in the viscerosensory zone; (2) the basal plate containing a number of evidently non-motor centers (superior and inferior olives). Nevertheless the "functional zonal model" has explanatory value. Thus, it is possible to interpret certain brain specializations related to particular behavioral profiles, as "local hypertrophies" of one or two functional columns. Recent developmental molecular studies on brains of birds and mammals confirmed the presence of longitudinal zones, and also showed molecularly defined transverse bands or neuromeres throughout development. The intersecting boundaries of the longitudinal zones and the transverse bands appeared to delimit radially arranged histogenetic domains. Because neuromeres have been observed in embryonic and larval stages of numerous anamniote species, it may be hypothesized that the brainstems of all vertebrates share a basic organizational plan, in which intersecting longitudinal and transverse zones form fundamental histogenetic and genoarchitectonic units.

Keywords: brainstem, gene patterns, histogenesis, longitudinal zones, morphological units, morphotype, neuromeres, topological analysis

\section{INTRODUCTION}

The brainstem or truncus cerebri forms the intermediate part of the vertebrate central nervous system. Rostrally, it borders on the diencephalon and caudally, it grades into the spinal cord

Abbreviations: Aoctl, area octavolateralis; caud, nucleus caudalis areae octavolateralis; cereb, cerebellum; cmsp, columna motoria spinalis; cnd, cornu dorsale; cnv, curnu ventrale; con, cochlear nuclei; crcb, crista cerebellaris; D, area dorsalis; dc, dorsal cell(s); desc, nucleus descendens of V; DL, area dorsolateralis; dors, nucleus dorsalis areae octavolateralis; effVIII, efferent octavus cells; egrl, eminentia granularis, pars lateralis; el org, electric organ; EW, nucleus of Edinger-Westphal; flm, fasciculus longitudinalis medialis; gc, griseum centrale; ic, inferior colliculus; int, nucleus intermedius areae octavolateralis; ip, nucleus interpeduncularis; is, nucleus isthmi; isth, isthmus rhombencephali c.q. isthmus neuromere; lc, locus coeruleus; lob el, lobus electricus; lob lin lat, lobus lineae lateralis; lob lin lat (el), electroreceptive part of lobus lineae lateralis; Lob lin lat (mech), mechanoreceptive part of lobus lineae lateralis; lobX, lobus vagi; lv, nucleus lateralis valvulae; mes, mesencephalic neuromere; meV, mesencephalic nucleus of V; mmpz, mesencephalic midventral proliferation zone; Mth, cell of Mauthner; Mü 1, 2 etc., cells of Müller; nucb, nucleus cerebelli; nuce, nucleus cuneatus externus; nucp, nucleus commissurae posterioris; nufl, nucleus funiculi lateralis; nuflm, nucleus of the fasciculus longitudinalis medialis; nufs, nucleus fasciculi solitarii; null, nucleus lemnisci lateralis; nuoma, nucleus octavomotorius anterior; nuomi, nucleus octavomotorius intermedius; nuomp, nucleus octavomotorius posterior; nurdV, nucleus of the radix descendens of V; nutegm, nucleus tegmentalis medialis; $\mathrm{nVI}$, nervus ab du cens $\mathrm{nX}$, nervus vagus; oli, oliva inferior; olsl, oliva superior, lateral nucleus; olsm, oliva superior, medial nucleus; pbn, parabrachial nuclei; pon, pontine nuclei; prom, nucleus
(Figure 1). It comprises derivatives of two of the three primary brain vesicles, the midbrain or mesencephalon and the hindbrain or rhombencephalon. The cerebellum, which develops

profundus mesencephali; Q, nucleus Q; r1, r2 etc., rhombomeres; "r7," "r8” etc., cryptorhombomeres; rai, nucleus raphes inferior; ras, nucleus raphes superior; rhlip, rhombic lip; ri, nucleus reticularis inferior; rism, nucleus reticularis isthmi et mesencephali; rlt, recessus lateralis tecti; rm, nucleus reticularis medius; rmes, nucleus reticularis mesencephali; rub, nucleus ruber; rubm, nucleus ruber, pars magnocellularis; rs, nucleus reticularis superior; sa, sulcus a; sc, superior colliculus; sid, sulcus intermedius dorsalis; sis, sulcus isthmi; siv, sulcus intermedius ventralis; $\mathrm{sl}$, sulcus limitans of His; slm, sulcus lateralis mesencephali; sm, somatomotor column; smi, sulcus medianus inferior; sms, sulcus medianus superior; snc, substantia nigra, pars compacta; spl, first spinal neuromere; ss, somatosensory column; t, taenia; tect, tectum mesencephali; teg, tegmentum mesencephali; tegl, nucleus tegmentalis lateralis; tl, nucleus tori lateralis; tlong, torus longitudinalis; tsc, torus semicircularis; $\mathrm{V}$, area ventralis; vem, nucleus vestibularis magnocellularis; vesn, vestibular nuclei; vm, visceromotor column; visc, nucleus visceralis secundarius; $\mathrm{VL}$, area ventrolateralis; vs, viscerosensory column; zglmv, zona granularis marginalis, pars lateroventralis; III, nucleus nervi oculomotorii; IIIc, nucleus nervi oculomotorii, pars caudalis ; IIIl, nucleus nervi oculomotorii, pars lateralis; IIIm, nucleus nervi oculomotorii, pars medialis; IIIp, nucleus nervi oculomotorii, pars periventricularis; IIIs, nucleus nervi oculomotorii, pars superficialis; IV, nucleus nervi trochlearis; Vm, nucleus motorius nervi trigemini; $\mathrm{Vpr}$, nucleus sensorius principalis nervi trigemini; $\mathrm{VI}$, nucleus nervi abducentis; VIIm, nucleus motorius nervi facialis; VIIIa, nucleus anterior nervi octavi; VIIId, nucleus descendens nervi octavi; IX(m), nucleus motorius nervi glossopharyngei; $\mathrm{X}(\mathrm{m})$, nucleus motorius nervi vagi; $\mathrm{Xmc}$, nucleus motorius nervi vagi caudalis; Xmr, nucleus motorius nervi vagi rostralis. 
ontogenetically as a dorsal outgrowth of the most rostral part of the rhombencephalon, "emancipates" itself from the brainstem to become a principal brain part in its own right. The cell masses in the brainstem include (a) centers of origin and/or termination of all cranial nerves except for I, (b) a central core of loosely arranged cells, known as the reticular formation, and (c) numerous relay nuclei. Prominent among the latter are the so-called precerebellar nuclei, which are intercalated in ascending and descending projections terminating in the cerebellum.

According to the classical studies of His $(1891,1893)$, which were carried out mainly on human embryonic material, the lateral walls of the central nervous system consist throughout their extent of two longitudinal zones or plates: the ventrally situated basal plate and the dorsal alar plate. His pointed out that the former contains the primary motor centers, whereas the primary sensory centers are found in the latter. The boundary between these two entities was found to be marked by a distinct ventricular groove, which he named the sulcus limitans. Somewhat later, the noted American comparative neuroanatomists Herrick (1899) and Johnston (1902a,b,c) concluded that, at the level of the brainstem, the basal, and alar plates can both be divided into two functional columns. Thus, they distinguished a somatomotor ventral column and a visceromotor intermedioventral column within the basal plate, and a viscerosensory intermediodorsal column and a somatosensory dorsal column within the alar plate (Figure 2A). Although Herrick and Johnston confined their study of the functional columns to anamniote species, they were convinced that their analyses had revealed a basic structural and functional plan, prevailing throughout the vertebrate kingdom. Herrick (1913) was the first to apply this columnar scheme to the human brainstem, which has since been promulgated in practically every textbook of neuroanatomy (Figure 2B). However, a critical study of the relevant literature (reviewed in Nieuwenhuys, 1998a) revealed that many important questions regarding the structural and functional organization of the brain stem are still open. This is simply because cross sections as such, do not show the rostrocaudal extent of ventricular sulci and cell zones. Questions still awaiting a definitive answer include: (1) Is the brainstem really divisible into a motor basal plate and a sensory alar plate? (2) Are the centers contained within the basal plate and the alar plate arranged in a longitudinal zonal pattern? (3) If so, are the boundaries of these zones marked by ventricular sulci? (4) Do nuclei, that fall under common functional denominators, fit into a longitudinal zonal pattern? (5) Does the midbrain show a longitudinal zonal pattern, and if so, does this pattern correspond to that in the rhombencephalon? In order to tackle these and other related questions, I (Nieuwenhuys, 1972, 1974) developed a procedure, named topological analysis, which makes it possible to survey the entire ventricular surface of the brainstem, with its sulci, and the underlying cell masses in a single reconstruction. With the aid of this procedure, the brainstems of the following 16 anamniote species have been analyzed: the lamprey Lampetra fluviatilis (Nieuwenhuys, 1972; Nieuwenhuys and Nicholson, 1998), the cartilaginous fishes Scyliorhinus canicula, Squalus acanthias, Raja clavata, and Hydrolagus colliei (Smeets and Nieuwenhuys, 1976; Smeets et al., 1983), the actinopterygian fishes Erpetoichthys calabaricus (Nieuwenhuys and Oey, 1983), Scaphirhynchus platorynchus (Nieuwenhuys, 1998c), Lepisosteus osseus (Nieuwenhuys and Pouwels, 1983), Amia calva (Heijdra and Nieuwenhuys, 1994), the lungfishes Lepidosiren paradoxa (Thors and Nieuwenhuys, 1979) and Neoceratodus forsteri (Nieuwenhuys, unpublished), the coelacanth Latimeria chalumnae (Kremers and Nieuwenhuys, 1979; Nieuwenhuys, 1998d)), the urodele amphibian Ambystoma mexicanum (Opdam and Nieuwenhuys, 1976), and the anuran amphibians Rana catesbeiana and Rana esculenta (Opdam et al., 1976), and Xenopus laevis (Nikundiwe and Nieuwenhuys, 1983).

The present paper consists of seven parts. In the first, the procedure followed will be outlined. In the second part, topological maps of the brainstem of two representative species, namely the lamprey L. fluviatilis, and the shovelnose sturgeon S. platorynchus, will be presented. In the third part, the principal results of the

\section{A}

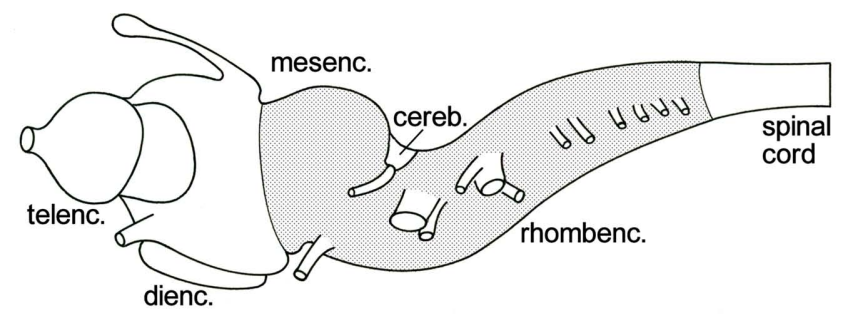

B

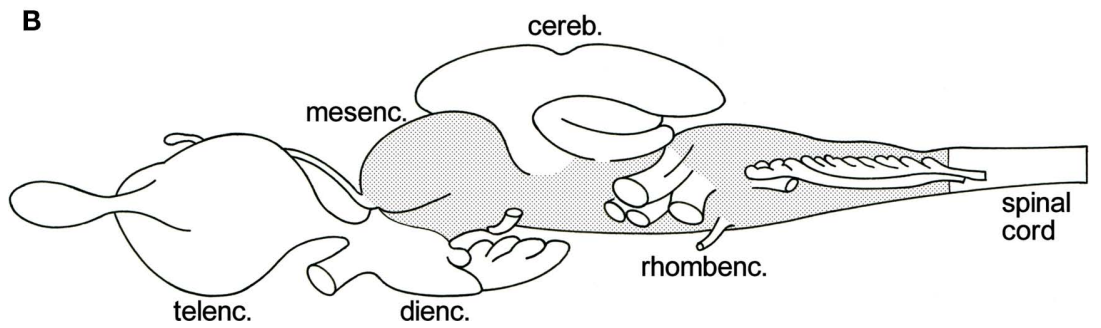

FIGURE 1 | Lateral views of the brains of the lamprey Lampetra fluviatilis (A), and the spiny dogfish Squalus acanthias (B). The brainstem, i.e., the mesencephalon plus the rhombencephalon minus the cerebellum, is stippled. 

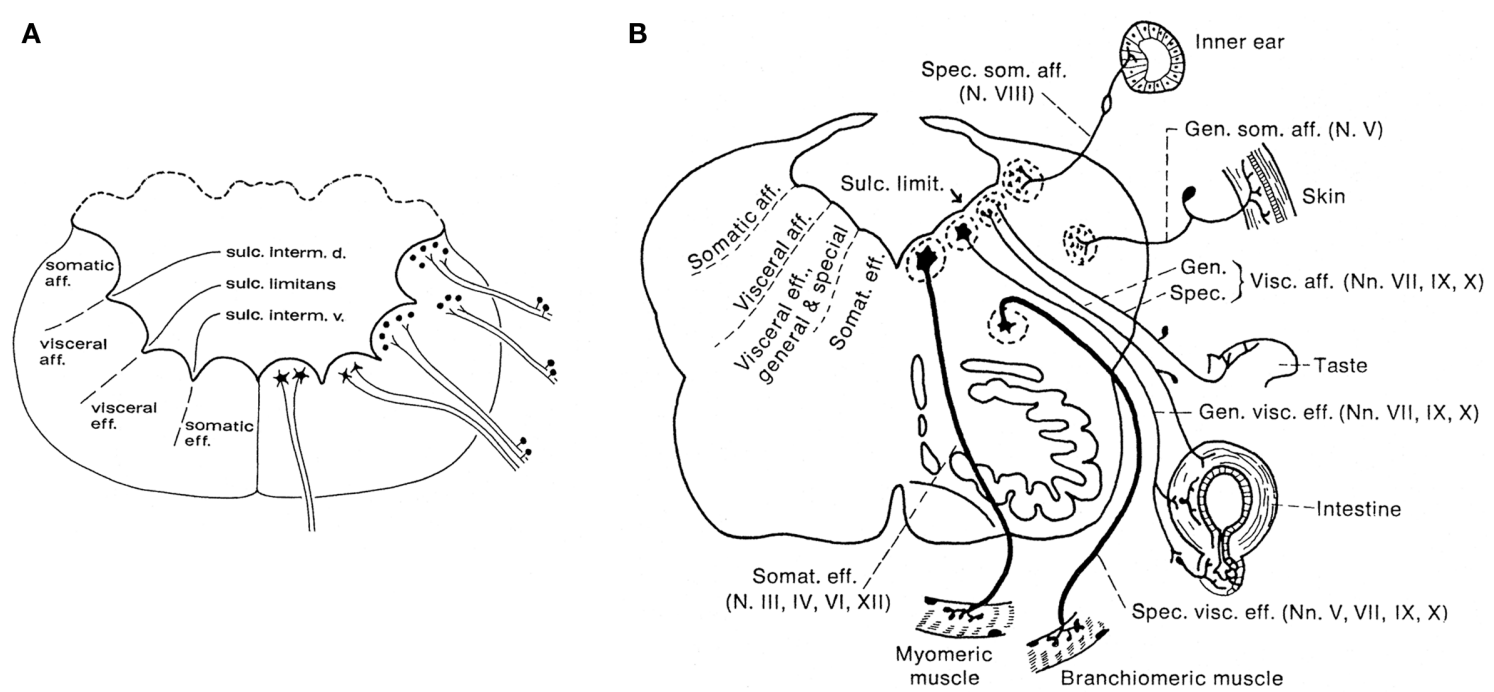

FIGURE 2 | Diagrammatic transverse sections through the rhombencephalon of an anamiote (A), and the human (B), to show the arrangement of the so-called functional columns.

project as a whole will be briefly discussed. In the fourth part, some functional correlations of the results of our topological analyses of the brainstem will be touched upon. In the fifth part, the significance of the topological approach for the study of the fundamental morphological pattern of the brainstem, as revealed by modern molecular studies, will be highlighted. In the sixth part, some general notes on the morphological interpretation of topological charts will be made, and in the seventh and final part, some perspectives for future research will be outlined.

\section{TOPOLOGICAL ANALYSIS OF THE BRAINSTEM}

The procedure followed is based on the observation that the central nervous system of vertebrates contains a built-in system of natural coordinates (Nieuwenhuys, 1998b). This natural coordinate system (NCS) includes: (a) two natural planes, i. e. the ventricular and meningeal surfaces of the neural tube, (b) a set of radially oriented curves, which connect these two surfaces, and (c) a set of tangential curves, which connect the floor and roof plates of the neural tube. The radial curves or vectors manifest themselves in the direction and orientation of: (i) the matrix cells, which during early development span the width of the walls of the neural tube, (ii) the radial glia cells, which are present during early neurogenesis in all vertebrates and throughout development in most anamniotes, and (iii) the blood vessels, which enter the walls of the neural tube radially across the meningeal surface. The tangential component of the NCS manifests itself in the course of "arcuate fibers," i. e. axonal processes which during early development, pass dorsoventrally, directly peripheral to the matrix layer. Numerous additional arcuate fibers are generated during further development. It is important to note that the processes of the radial glia cells and the arcuate fibers form important substrates for the radial and tangential migrations of neuroblasts that will come up in this and later sections of the present paper.
The material required for a topological analysis consists of one or more perfect, continuous series of transverse sections through the brainstem of the species to be studied, stained for neuronal perikarya (Nissl). The optimal thickness of the sections is $20 \mu \mathrm{m}$.

The procedure involves the following sequence of steps (Figure 3):

1. Forty equidistant sections are selected for a preliminary analysis. These sections are photographed and printed at a magnification of $30 \times$.

2. The sections selected are analyzed as follows: (a) The deepest points of the ventricular sulci are marked. (b) The cell masses (and large individual cells) are delineated. These structures are projected on the ventricular surface with the aid of tangent radial curves. Because during ontogeny most cell masses in the central nervous system migrate radially outward from their respective matrix zones, it is reasonable to assume that, by the procedure followed, these entities are projected back to their primary topological position. (c) At the ventricular side the raphe corresponds to a distinct groove, the sulcus medianus inferior. In each section the deepest point of this sulcus is defined as the zero point. (d) With the use of a curvimeter, the distance from this zero point to the deepest points of other sulci and to the projections of the outlines of the cell masses are measured along the ventricular surface on either side. (e) All the distances measured in each individual section are now plotted on a line. Thus, the end product of the analysis of each individual section is a straight line on which the deepest points of ventricular sulci and the projections of cell masses are plotted.

3. A system of coordinates is introduced, consisting of a central vertical line, termed the axis, crossed by 40 equidistant horizontal lines. The distance of these horizontal lines depends on the total number of sections between the first and the last of the 40 selected sections, the thickness of the individual sections, and the magnification chosen. 


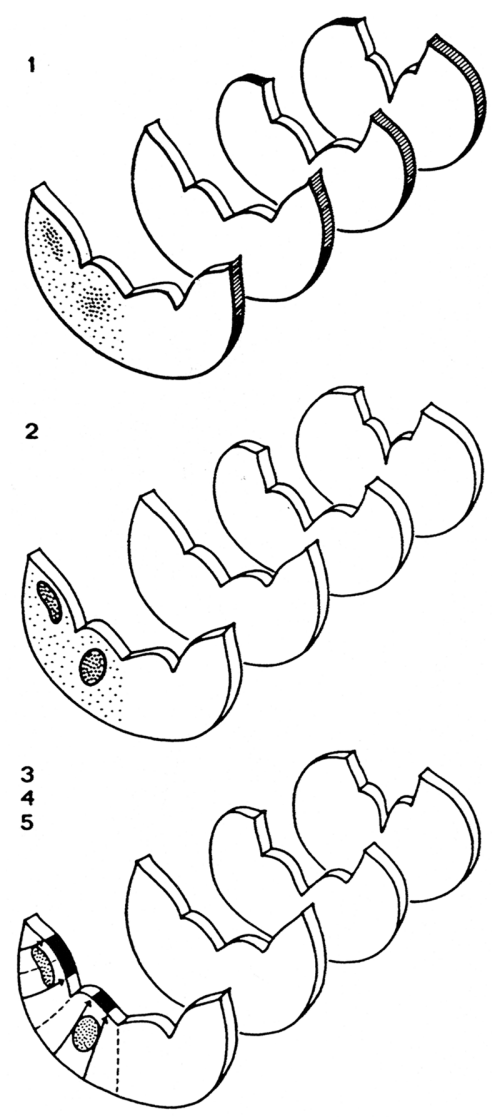

FIGURE 3 | Steps involved in the preparation of a topological reconstruction of the brainstem: (1) selection of sections; (2) drawing of sections and delineation of cell masses; (3) introduction of radial curves derived from the natural system of coordinates; (4) drawing of tangent curves; (5) projection of cell masses upon the ventricular surface; (6) transformation of the curvilinear profile of the ventricular surface into a
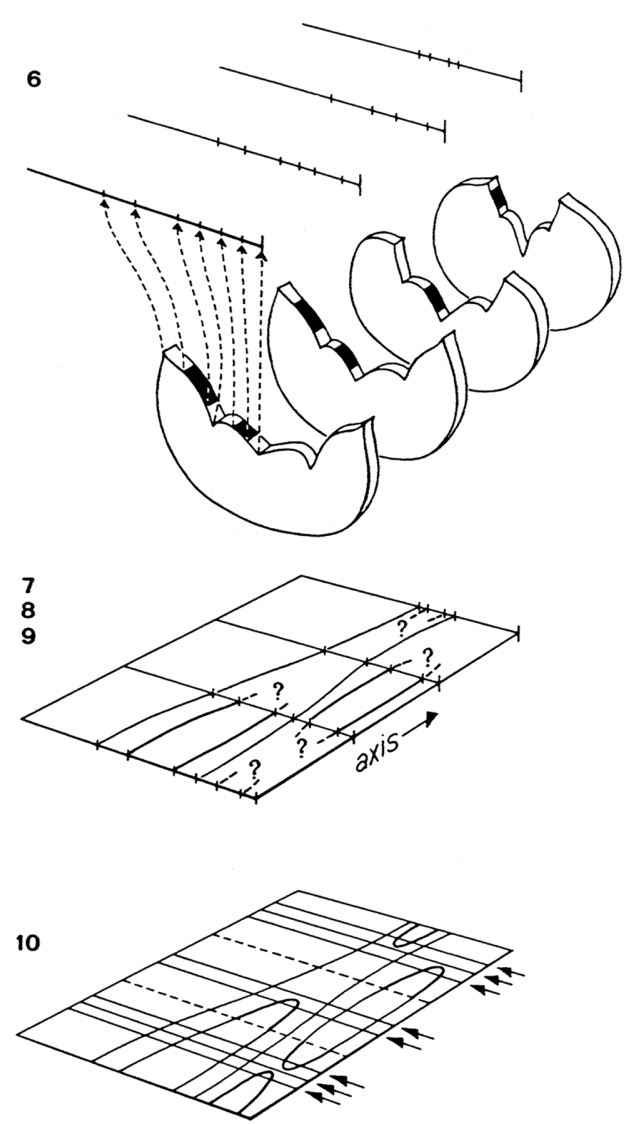

straight line; (7) introduction of an orthogonal system of coordinates; (8) transfer of the lines representing the ventricular surfaces of the sections to the coordinate system; (9) connection of corresponding points; (10) collection of additional data concerning the beginning and the end of ventricular sulci and cell masses, and completion of the reconstruction.

In the procedure described, the three-dimensional structure of a given brainstem is reduced to a two-dimensional chart; hence, one dimension, namely the thickness of the structure analyzed, had to be sacrificed. In order to compensate somewhat for this limitation, I have adopted the convention to allocate the cell masses to three categories: periventricular, intermediate, and submeningeal, and to indicate the nuclei of these categories by continuous-, dashed-, and dotted curves, respectively.

\section{TOPOLOGICAL CHARTS OF TWO REPRESENTATIVE SPECIES}

In this section, the results of the topological analyses of the brainstems of two representative species, the lamprey $L$. fluviatilis, and the shovelnose sturgeon S. platorynchus, will be presented first, and then the principal results of the project as a whole will be summarized.

Lampreys (and the related hagfishes) are the only extant jawless vertebrates (agnathans) and thus represent the sister group of gnathostome vertebrates (Figure 4A). Although these animals have a long independent phylogenetic history behind them, their small and simple brains form an optimal starting point for studies on the evolution of the vertebrate central nervous system 


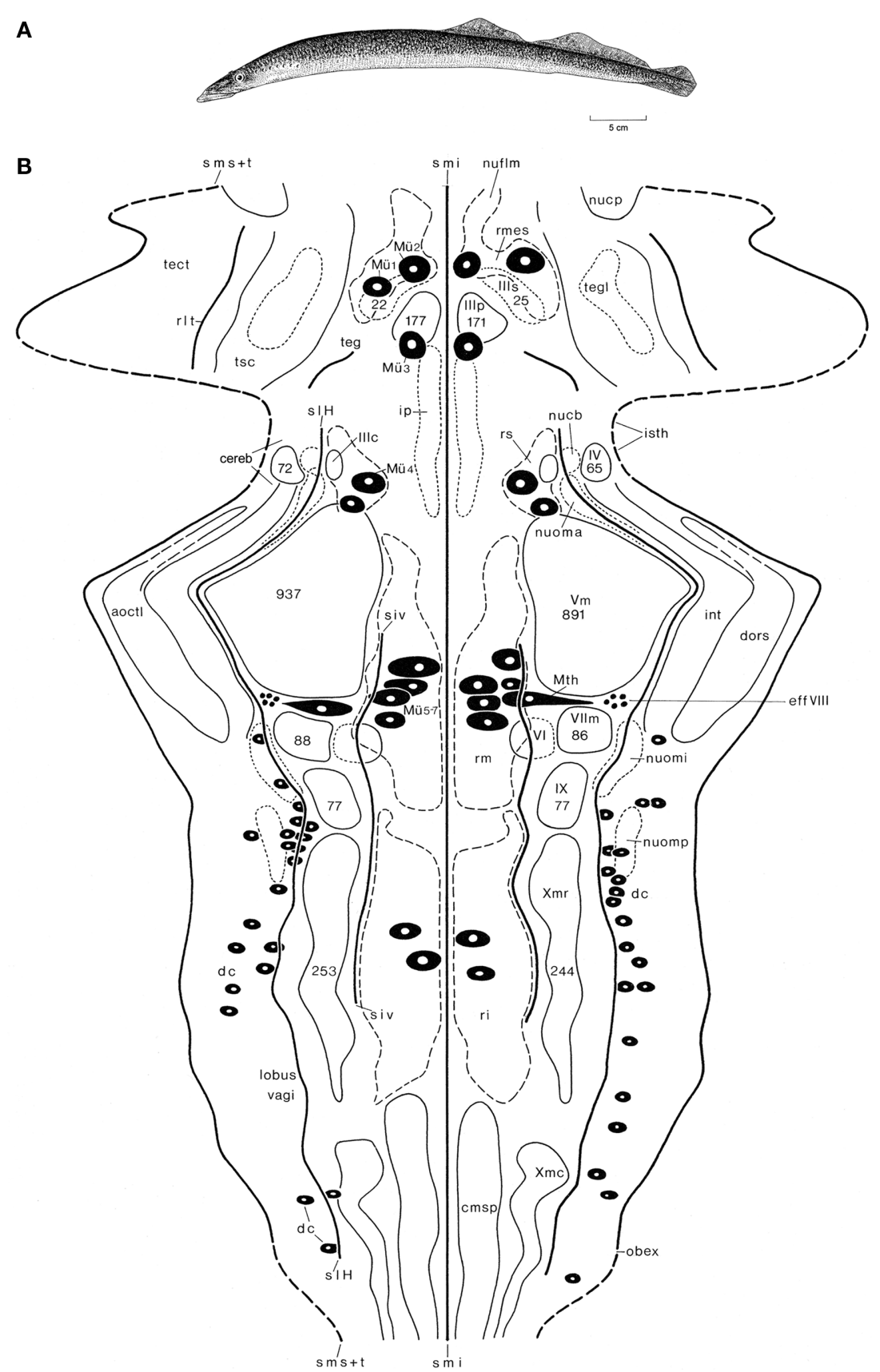

FIGURE 4 |The lamprey Lampetra fluviatilis. Holotype (A), and topological chart of the brainstem (B). The numbers of cells, present in some nuclei are, indicated by numerals enclosed within the outline of the structure. Modified from Nieuwenhuys and Nicholson (1998).

(Figure 1A). In our topological analyses of the brainstem of L. fluviatilis (Nieuwenhuys, 1972; Nieuwenhuys and Nicholson, 1998; Figure 4B), it appeared to be possible to map the entire brainstem, including the tiny cerebellar plate (Figure 1A) and the tectum mesencephali. The following six ventricular sulci could be mapped: sulcus medianus inferior, sulcus intermedius ventralis, sulcus limitans of His, a short unnamed, oblique sulcus in the isthmus region, recessus lateralis tecti, and the sulcus medianus superior. The lateral margin of the chart is formed by a curve, consisting of alternating dashed and continuous parts. The dashed parts represent the sulcus medianus superior, whereas the continuous parts represent the lines of attachment of the choroid roofs of the rhombencephalon and mesencephalon. The mesencephalic choroid roof is a unique feature of lampreys.

Some 20 different cell groups could be delineated and charted. Most of these represent primary afferent and primary efferent nuclei. A number of centers of higher order could also be distinguished. Prominent among these are the mesencephalic and 


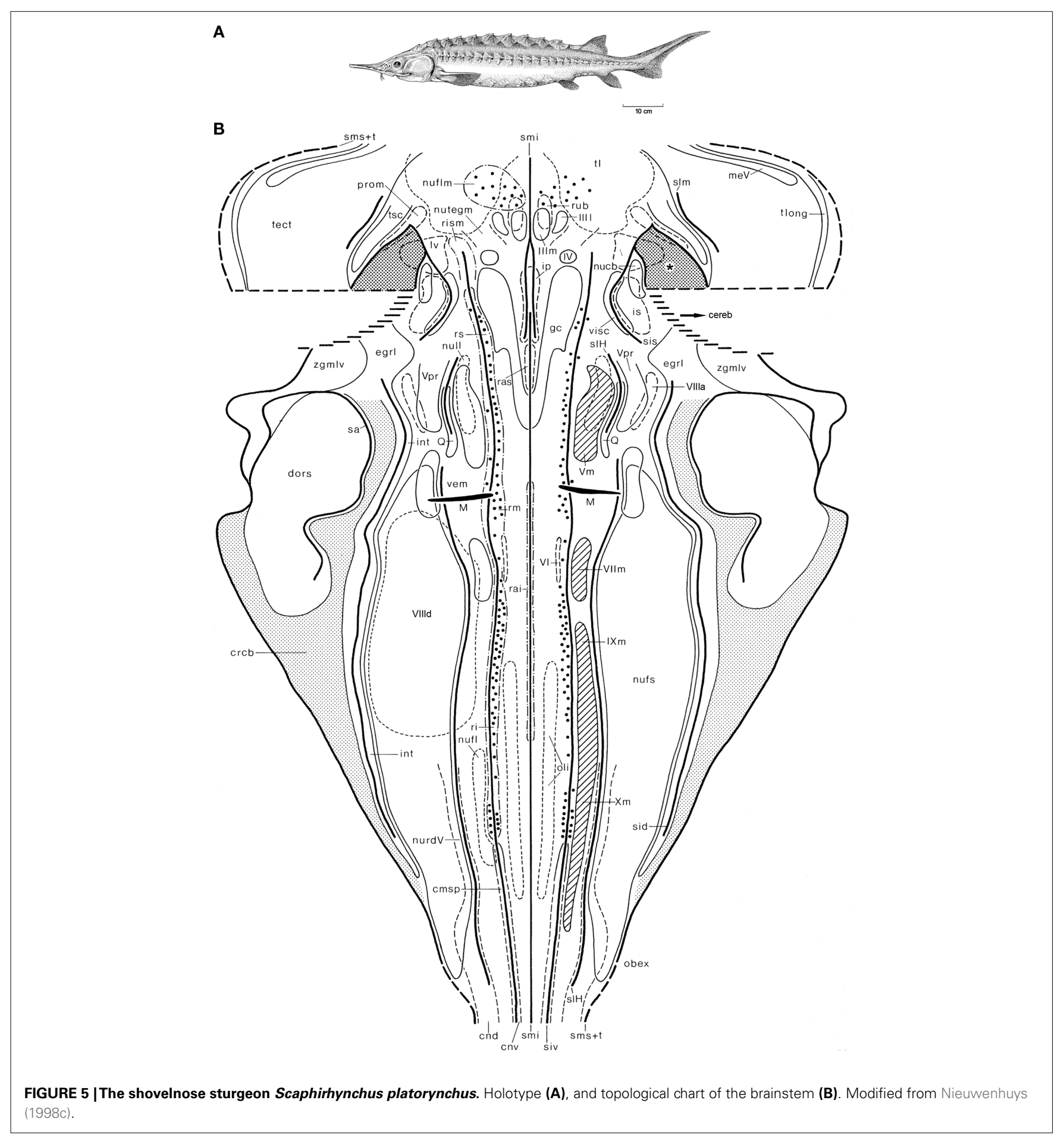

rhombencephalic reticular nuclei, the nucleus tegmentalis lateralis, the interpeduncular nucleus, and nucleus cerebelli. Other relay nuclei, such as the nucleus funiculi lateralis and the inferior olive, which can be clearly distinguished in most gnathostomes, were not identified in the lamprey. It is remarkable that the trochlear nucleus lies far dorsally and is embedded in the alar plate rather than in the basal plate. This is another unique feature of lampreys. In addition to cell masses, a number of large neurons could be mapped individually. These include the cells of Mauthner (Mth), four groups of large reticular elements among which seven typical cells of Müller (Mü 1-7), and a number of primary somatosensory neurons. The latter are situated in the intermediate and caudal parts of the rhombencephalic alar plate and correspond to the spinal dorsal cells (dc). Another group of central primary somatosensory neurons, viz. the mesencephalic trigeminal nucleus, which is present in all gnathostomes, is lacking in lampreys. 
The shovelnose sturgeon S. platorynchus (Figure 5A) is a member of the chondrosteans, a small group of ancient and rather primitive actinopterygian fishes. The structure of the brainstem of this fish is much more complex than that of the lamprey, as appears from the fact that some 40 cell masses, rather than only 27 found in the former, could be delineated (Nieuwenhuys, 1998c). The large cerebellum, which is partly invaginated into the fourth ventricle, was not included in our chart (Figure 5B), and the same holds true for the caudal part of the tectum. A rostral part of the cerebellum, i.e., the valvula cerebelli, invaginates into the mesencephalic ventricle. Laterally, the invaginated valvula is fused with part of the ventricular surface of the tegmentum mesencephali. The area of fusion of these two structures is indicated in the chart as a dotted field, marked by an asterisk. Throughout most of the rhombencephalon of the sturgeon, three distinct ventricular grooves bilaterally mark the boundaries of four longitudinal zones or columns. In the mesencephalon a zonal pattern is less clear. The Mauthner cells and the large elements in the reticular formation could be mapped individually. However, in order to avoid crowding, only every fifth large reticular element is included in the chart.

In the next section, reference will be frequently made to the two topological charts just shown. It should be kept in mind, however, that the synopsis of our principal results presented there, is based on topological analyses of the brainstems of 16, rather than two, anamniote species.

\section{SYNOPSIS OF THE PROJECT AS A WHOLE}

The principal results of the project as a whole can be summarized as follows:

1. The rhombencephalon can be divided into a basal plate and an alar plate. The boundary between these two entities is in all species studied marked by a sulcus limitans (Figures $4 \mathrm{~B}$ and 5B).

2. The designation of the alar plate as "sensory" and the basal plate as "motor" is correct insofar that all primary afferent centers are situated within the former and all primary efferent centers within the latter. A notable exception to this rule is that in lampreys, as already mentioned, the somatomotor trochlear nucleus is situated in the alar plate (Figure 4B).

3. The basal plate can be divided into a medial zone or column and an intermediomedial zone or column.

4. The boundary between the two morphological entities mentioned under 3 is in almost all species studied at least partially marked by a sulcus intermedius ventralis (Figures $4 \mathrm{~B}$ and $5 \mathrm{~B}$ )

5. The medial zone can be characterized as somatomotor, because it harbors the motor nuclei of IV, VI and, where present, XII, as well as the rostral end of the spinal motor column.

6. The medial zone contains a number of cell masses, which can be designated as somatomotor coordinating centers. These include the superior, medius, and inferior reticular nuclei, and the superior and inferior raphe nuclei. Raphe nuclei could not be detected in the lamprey, however.

7. The medial zone contains a number of evidently nonsomatomotor relay centers, including the interpeduncular nucleus and the inferior olive. The latter is, as already mentioned, lacking in the lamprey.

8. The functional designation of the intermedioventral zone as visceromotor is justified, because it contains in all species studied a conspicuous series of primary visceromotor cell masses, formed by the motor nuclei of V, VII, IX, and X (Figures 4B and 5B).

9. However, the intermedioventral zone contains, just as the medial zone, a number of structures, which do not accord with its functional label. These include the Mauthner neuron, the efferent nucleus of the VIIIth nerve (Figures 4B and 5B), the precerebellar nucleus of the funiculus lateralis, and the superior olive (in anurans) and the nucleus of the lateral lemniscus, two auditory (and, hence special somatosensory) relay nuclei.

10. The alar plate can be divided into an intermediodorsal zone or column and a dorsal zone or column.

11. The boundary between the two morphological entities mentioned under 10 is in many species at least partially marked by a sulcus intermedius dorsalis.

12. The caudal part of the intermediolateral zone contains a center known as lobus vagi (Figure 4B) or nucleus fasciculi solitarii (Figure 5B), which receives viscerosensory fibers via the VIIth, IXth, and Xth cranial nerves, whereas the most rostral part of the same zone harbors a cell mass which, as its name: nucleus visceralis secundarius indicates, represents a viscerosensory center of higher order (Figure 5B). It would be incorrect, however, to designate the entire intermediolateral zone as viscerosensory, because it contains several general somatosensory centers and special somatosensory centers as well. The general somatosensory centers include the very diffuse nucleus tractus descendens of the trigeminal nerve (Figure 5B), the nucleus princeps of the same nerve (Figure $5 \mathbf{B}$ ) and, in lampreys, the primary somatosensory dorsal cells (Figure 4B). The special somatosensory component of the intermediodorsal zone is formed by a series of three to five cell masses extending from the level of the motor trigeminal nucleus to the level of entrance of the caudal roots of the vagus nerve. The names of these cell masses differ somewhat among the various anamniote groups. In Scaphirhynchus three of such cell masses, the anterior octavus nucleus, the magnocellular vestibular nucleus, and the descending octavus nucleus, could be delineated (Figure 5B). In Lampetra, the three octavomotor nuclei (Figure 4B) belong to the same functional category.

13. The dorsal zone of the rhombencephalon may be aptly designated as somatosensory, because it contains throughout most of its extent exclusively cell masses belonging in this functional category. These cell masses include: (1) the nucleus dorsalis areae octavolateralis, an electroreceptive lateral line center, occurring in lampreys, most groups of fish and all urodele amphibians (Figures $4 \mathrm{~B}$ and 5B); (2) the nucleus intermedius areae octavolateralis, a mechanoreceptive lateral line center, occurring in all groups of anamniotes, except for anuran amphibians (Figures $4 \mathbf{B}$ and $5 B$ ), and (3), in anurans, the nucleus dorsalis nervi octavi. It is important to note, however, that the nucleus cerebelli and the nucleus isthmi, two cell masses situated in the most rostral part 
of the rhombencephalic dorsal zone, cannot be classified as somatosensory centers.

14. The mesencephalon consists of the ventral tegmentum mesencephali and the dorsal tectum mesencephali. The rhombencephalic basal plate is rostrally continuous with the medial part of the tegmentum mesencephali, which has been designated on that account as the motor tegmentum. It contains the nuclei, the third cranial nerve, the nucleus of the fasciculus longitudinalis medialis and, in many species, the nucleus ruber (Figure 5B). The rhombencephalic alar plate passes over into the lateral part of the tegmentum and the tectum. Contrary to the statements of numerous previous authors, including Holmgren and van der Horst (1925), Gerlach (1933, 1947), Addens (1933) and Heier (1948), the sulcus limitans does not extend into the midbrain (Figures $4 \mathbf{B}$ and $5 \mathbf{B}$ ). The lateral part of the tegmentum and the tectum are both the recipients of important somatosensory pathways. The lateral tegmentum contains a large special somatosensory relay center, the torus semicircularis. The tectum mesencephali is to be considered as a general and special somatosensory correlation center of higher order. However, in all gnathostomes it also contains a primary somatosensory cell group: the nucleus mesencephalicus of $\mathrm{V}$ (Figure 5B).

Summarizing again: as indicated by Wilhelm His, the entire brainstem (i. e. the rhombencephalon plus the mesencephalon) can be divided into a primarily motor basal plate and a primarily sensory alar plate. A sulcus limitans, marking the boundary of the basal and alar plates on the ventricular side, is confined to the rhombencephalon. Within the rhombencephalon four morphological zones, which are designated here as area ventralis, area intermedioventralis, area intermediodorsalis, and area dorsalis, can be distinguished. The areae ventralis and intermedioventralis form together the rhombencephalic basal plate, whereas the areae intermedioventralis and dorsalis form together the rhombencephalic alar plate. The four morphological entities mentioned correspond largely, though not entirely, with the four functional zones or columns - somatomotor, visceromotor, viscerosensory, and somatosensory - of Herrick and Johnston (Figure 2A). This is so because all of the four morphological zones contain one or more cell masses, the functional significance of which do not mesh with the functional label of the pertinent zones.

\section{FUNCTIONAL CORRELATIONS}

Although the topological charts as such are representations of morphological data, many of the features shown by them refer directly to functional or behavioral aspects. Thus, the extraordinarily large size of the motor trigeminal nucleus in lampreys (Figure 4B) has to do with the fact that in these jawless animals the nerve in question innervates the musculature of the large sucking mouth, with which they attach themselves to and attack fish. The large size of the nucleus of the fasciculus solitarius in sturgeons (Figure 5B) is related to the strong development of the gustatory system. In these bottom-dwelling fishes, taste buds are not confined to the oral cavity, but also occur on the barbels and the tentacular fringes, that surround the mouth. These external taste organs play an important role in locating food. The large size of the nucleus dorsalis areae octavolateralis in sturgeons (Figure 5B) indicates that in these fishes the electroreceptive lateral line system is also well developed. Some further examples of such "central responses" to particular peripheral differentiations will now be discussed. In order to place these various "central responses" into perspective, the brains of the various specialized species to be discussed are in Figure 6 compared with those of related, "more generalized" species. Thus, the brain of the electric ray Torpedo ocellata (Figures 6D-F) is compared to that of the spiny dogfish $S$. acanthias (Figures 6A-C), whereas the brains of three very specialized teleosts, viz. the cyprinid Carassius carassius (Figures 6K-M), the African notopterid Xenomystus nigri (Figures $6 \mathbf{N}-\mathbf{P}$ ), and the gymnotid Eigenmannia virescens (Figures 6Q-S) are compared to that of the holostean A. calva (Figures 6G-H).

1. In electric rays, such as Torpedo, the musculature of the expanded pectoral fins has been largely transformed into a pair of powerful electric organs (Figure 6D). These organs are innervated by branches of the VIIth, IXth, and Xth cranial nerves. Accordingly, the motor nuclei of these nerves, which constitute together the caudal portion of the rhombencephalic visceromotor column, consist mainly of large electromotor neurons and constitute collectively a pair of gigantic electric lobes (Figures 6E,F). In electric rays, the discharge of the electric organs is both a means of protection and a device for stunning prey.

2. In cyprinid teleosts, such as the common goldfish Carassius (Figure 6K), the gustatory system is well developed. Taste buds are scattered over the entire body, but the most specialized part of the gustatory system of these animals is the so-called palatal organ, which is situated in the roof of the mouth. This organ does not only bear an abundance of taste buds, but is also provided with a layer of muscle fibers. It is involved in the selection of food particles from substrate material (Sibbing 1984; Finger 1988; Ikenaga et al., 2009). The taste buds of the palatal organ are innervated by afferent fibers of the vagus nerve, and its musculature is supplied by efferent fibers of the same nerve. The computational aspects of the sophisticated food detection and selection just outlined, are carried out by the adjacent, vagal segments of the viscerosensory and visceromotor columns, which in cyprinids form together a pair of large and highly differentiated vagal lobes (Figures 6L,M).

3. A lateral line system is present in all anamniotes, except for adult anuran amphibians. The fibers, which carry the impulses from the lateral line organs centrally pass, by way of the anterior and posterior lateral line nerves to the most dorsal part of the rhombencephalic alar plate, where they terminate in an elongated intraventricular protrusion, known as the lateral line lobe. The lateral line receptor organs are of two kinds, mechanoreceptive and electroreceptive. The mechanoreceptive lateral line sense organs are hydrodynamic detectors, capable of detecting water movements. Most electroreceptive lateral line organs belong to a category known as ampullary organs. These organs respond to low frequency, low voltage signals, which surround 


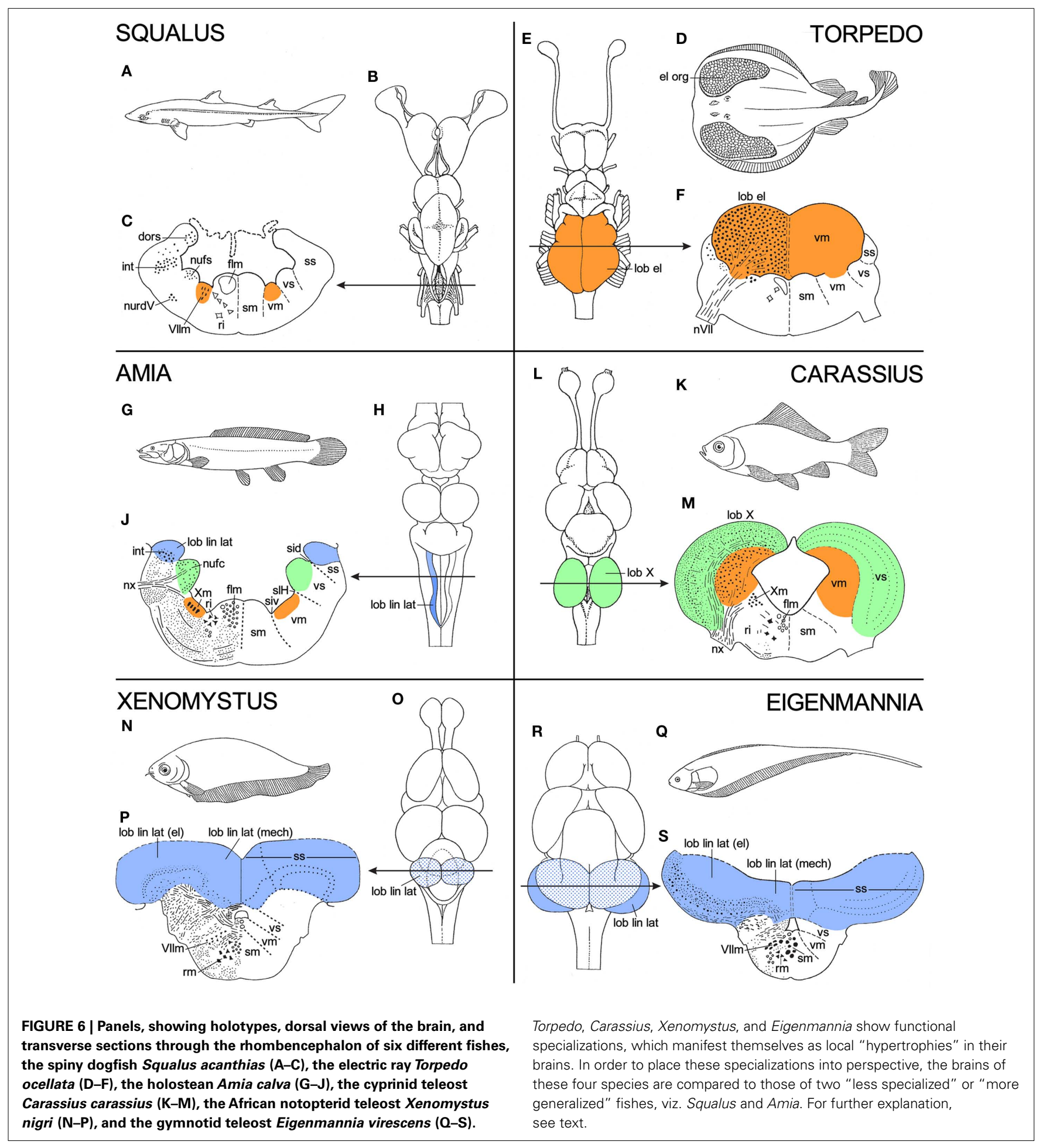

many aquatic animals. By means of this receptor system, many fishes are able to detect the electric fields produced by prey fish and social partners. Fishes which possess only ampullary organs may be designated as "passive" electric fishes, which means that they are only able to detect electrical fields produced by other fish. However, two groups of teleosts with electroreceptors, the Gymnotidae and the Mormyridae, can be characterized as "active" electric fish, because they are able to detect signals which they emit themselves with an electric organ. They use their electric system for what may be called active electrolocation as well as for conspecific electrocommunication. The detection of the impulses, generated by the electric organs can be assigned to a special type of electric lateral line receptors, known as tuberous organs. 
In Figure 6, "non-electric" bony fishes (i.e., fishes possessing only a mechanoreceptive lateral line system), "passive" electric bony fishes, and "active" electric bony fishes are represented by the bowfin $A$. calva, the false featherback $X$. nigri, and the glass knifefish E. virescens, respectively. In Amia (Figure 6G), the mechanoreceptive lateral line fibers terminate in a slender, elongated lateral line lobe (Figures $\mathbf{6 H} \mathbf{H} \mathbf{J})$. In Xenomystus (Figure $\mathbf{6 N}$ ), the lateral line lobe is larger and more compact than in Amia (Figure 6O). The mechanoreceptive fibers terminate in the smaller, medial part of this lobe, whereas the electroreceptive fibers terminate in its larger, lateral part (Figure 6P). In Eigenmannia (Figure 6Q), finally, the primary lateral line center is grown out to a huge, everted disk (Figures 6R,S), in which the afferents from the mechanoreceptive, "passive" electroreceptive, and "active" electroreceptive sense organs terminate in strictly separated compartments (see Meek and Nieuwenhuys, 1998, for details).

Summa summarum: the brainstem of anamniotes shows a distinct longitudinal zonal pattern. In the rhombencephalon four different morphological zones: ventral, intermedioventral, intermediodorsal, and dorsal are present, whereas in the mesencephalon three of such zones: medial tegmental, lateral tegmental, and tectal can be discerned. These longitudinal morphological zones correspond largely, though not entirely, with the functional columns of His, Herrick, and Johnston. Because of this parallelism, our topological charts do not only provide morphological information, but also functional information. In many anamniote species, local enlargements of one or more functional columns are coupled with the strong development of particular sense systems or effector organs, and these are in turn correlated with specialized behavioral profiles.

\section{SIGNIFICANCE OF THE TOPOLOGICAL APPROACH FOR THE STUDY OF THE FUNDAMENTAL MORPHOLOGICAL PATTERN OF THE BRAINSTEM AS REVEALED BY MODERN MOLECULAR STUDIES}

From the foregoing, it may be concluded that the brainstem of anamniotes contains a number of longitudinally oriented zones or columns, and the fact that these morphological entities are present in representatives of all major anamniote groups indicates that they form part of the fundamental morphological pattern or morphotype of the brainstem. The causal underpinning of this feature apparently relates to shared processes of dorsoventral patterning (columnar zonation), neurogenesis, and histogenesis. The question arises whether this longitudinal zonal pattern represents the entire structural plan, or whether other structural features, because of their constant occurrence, can also be incorporated in it. At the beginning of the twentieth century, it was well known that the central nervous system shows clear signs of segmentation during early development (Von Kupfer, 1906; Figure 7). Throughout most of the twentieth century, these neural segments or neuromeres were generally considered as transitory phenomena, which apparently had no relation whatsoever with the definitive structural and functional plan of the central nervous system. However, thanks to the pioneering work of the Swedish neuroembryologists Bergquist and Källen, and numerous recent studies, we know now that this view was wrong, and that neuromeres and their derivatives in the adult brains represent fundamental morphological entities that likewise bear upon functional peculiarities or specializations detected along the AP dimensions of the longitudinal columns.

Bergquist and Källén (numerous publications summarized in Bergquist and Källén (1954), and Nieuwenhuys (1998a)) systematically studied the ontogeny of the brain in representatives of all vertebrate groups. They found that neuromeres are present during a certain developmental period in all vertebrates. They coincide with bands of high mitotic rate and, hence with zones of proliferation. Three successive waves of such transversely oriented zones of proliferation pass over the embryonic neuraxis, forming proneuromeres, neuromeres, and postneuromeres or transverse bands, respectively. Shortly after the start of the third or postneuromeric wave, longitudinal zones of high mitotic activity are formed. Four of these zones, designated as the dorsal, the dorsolateral, the ventrolateral, and the ventral columns could be distinguished in the anlage of the rhombencephalon. The dorsal column appeared to be confined to the rhombencephalon, the ventral column was observed to extend into the mesencephalon,
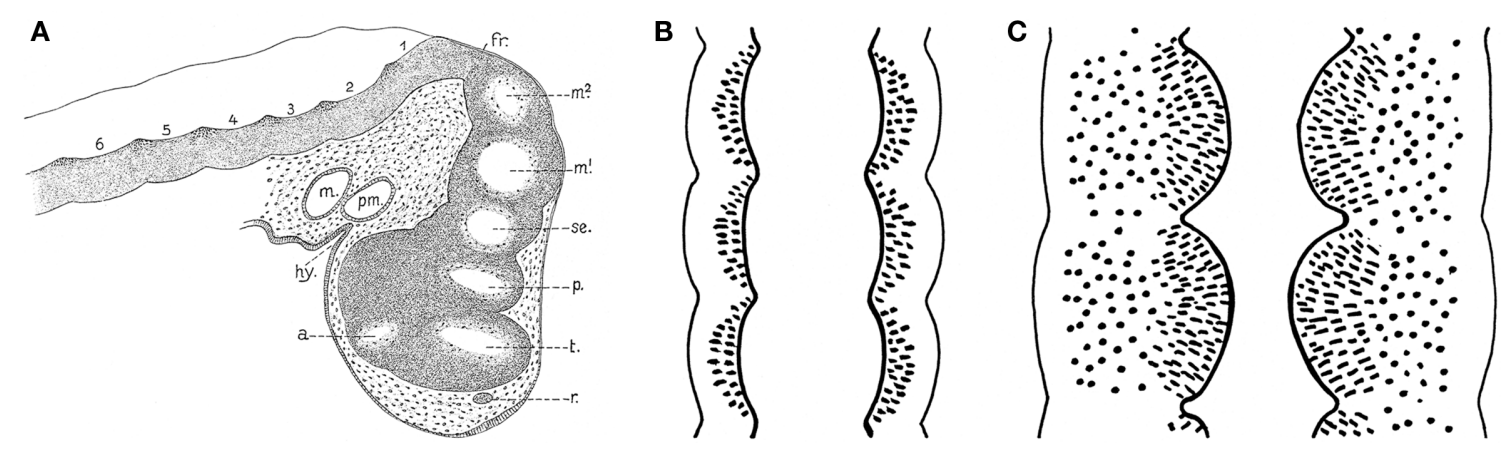

FIGURE 7 | Signs of segmentation in the brains of vertebrate embryos c.q. larvae. (A) Sagittal section through the brain of a 10-mm larva of the spiny dogfish Squalus acanthias. a, optic stalk; fr, fissura

rhombo-mesencephalica; hy, hypophysis; $\mathrm{m}$, mandibular cavity; $\mathrm{m} 1, \mathrm{~m} 2$, mesomeres; $p$, parencephalon; pm, premandibular cavity; $r$, wall of olfactory groove; se, synencephalon; t, telencephalon; 1, 2 etc., rhombomeres.
Reproduced from Von Kupfer (1906). (B) Diagrammatic horizontal section through the neuraxis of an early embryo. Each neural segment or neuromere is separated from its neighbors by external vertical constrictions, which correspond to internal sharp dorsoventral ridges. (C) Similar section through the neuraxis of a later developmental stage, in which the neuromeres present themselves as distinct and sharply separated intraventricular bulges. 
whereas the remaining two columns could be traced into the forebrain. By intersection of the transverse bands and the longitudinal zones a chequered network develops, made up of squares with a high proliferative activity (Figure 8A). As far as the longitudinal columnar organization of the brainstem is concerned, the scheme of Bergquist and Källén closely resembles the pattern revealed by our topological analyses. It should be noted, however, that in the parcellation of Bergquist and Kállën, the boundaries between the various columns are not marked by ventricular sulci, but rather by "incisures" in the mantle layer. Topological analyses of the brainstems of embryonic and larval vertebrate species are required to determine the precise relationships between the results of the two approaches.

Bergquist and Källén (1954) designated the squares with high proliferative activity as migration areas. They noted that these areas show a remarkable consistency in both number and pattern throughout the vertebrate kingdom. On that account, they considered the migration areas to be fundamental morphological units, providing a sound basis for the homologization of neural grisea. These units represent three-dimensional radial complexes, stretching from the ventricular to the meningeal surface, within the confines of which the principal histogenetic events, i.e., proliferation, migration, and differentiation, essentially take place (Figure 8B). It is important to note that the boundaries of the units, as well as the migration of neuroblasts within them, strictly adhere to the vectors of the natural system of coordinates, discussed in Section "Topological Analysis of the Brainstem" of the present paper. During the last decades, the remarkable results of the pioneering studies of Bergquist and Källén have been confirmed and extended by numerous publications, as may appear from the following synopsis.

1. Segmental organization of early developing cells and cell groups. It has been observed that in the brainstem of teleosts, early developing primary motoneurons, as well as reticulospinal neurons show a distinct segmental distribution (Metcalfe et al., 1986; Hanneman et al., 1988; Bass et al., 2008). A segment-related pattern of organization has also been observed in the embryonic

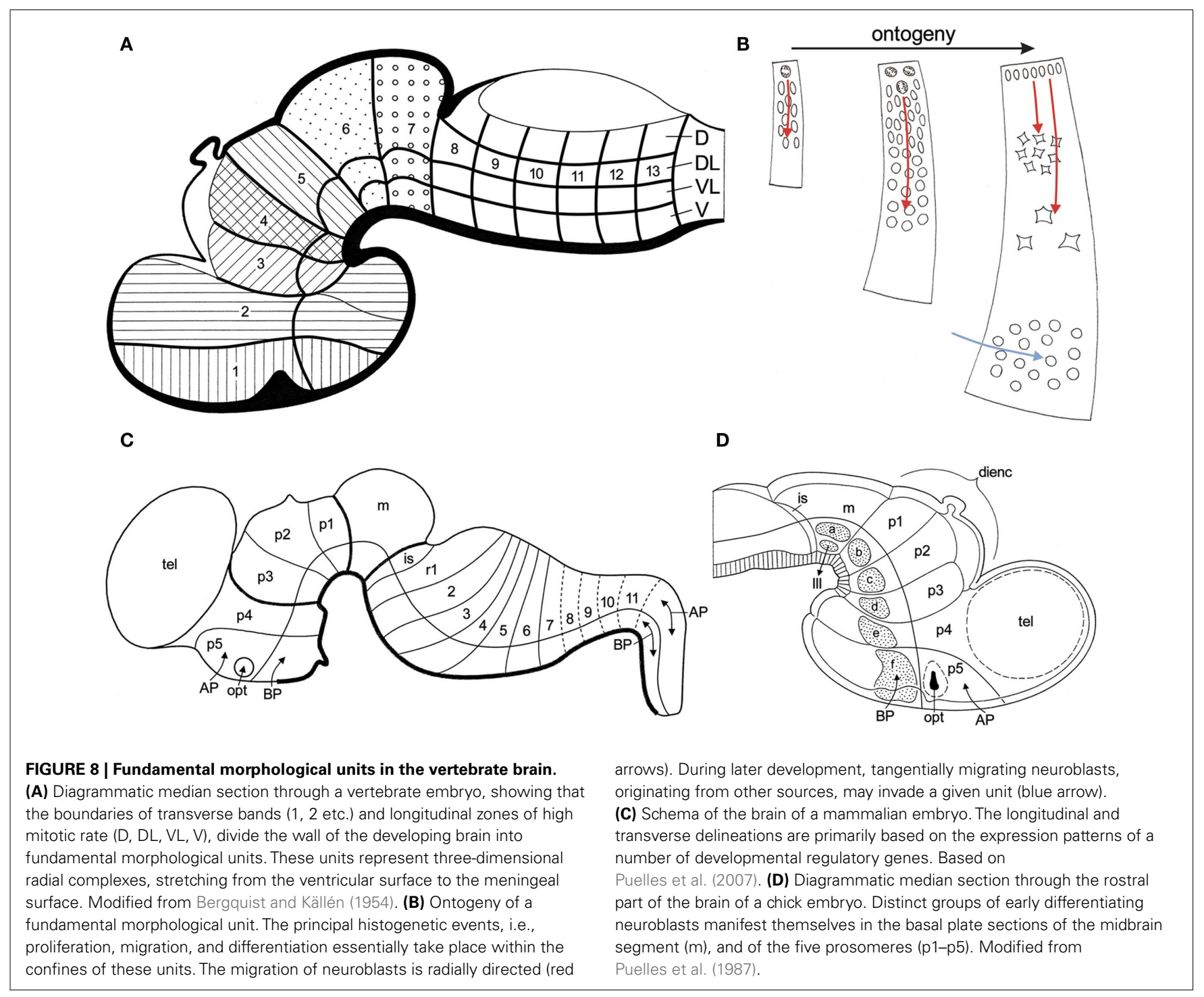


chick brain, where early differentiating neuroblasts were found to appear as separate, distinct groups at the center of the basal plate portions of the mesencephalic and prosencephalic neuromeres (Puelles et al., 1987; Figure 8D). It is remarkable that these groups of early differentiating neurons fit into a transverse, neuromeric as well as in a longitudinal zonal pattern, and therewith in the organizational scheme of Bergquist and Källén (Figure 8A).

2. Segmental cell lineage restrictions. As early as 1887, Orr (1887), p. 335) presumed that "the cells of one neuromere do not extend into another neuromere." This presumption has been substantiated by cell-marking experiments on the rhombencephalon (Fraser et al., 1990), and diencephalon (Figdor and Stern, 1993) of chick embryos, which showed that the progeny of individually labeled matrix cells failed to cross interneuromeric borders. Marín and Puelles (1995) and Wingate and Lumsden (1996) used quail-chick grafting chimaeras to examine the fate of individual neuromeres. Fate mapping revealed that the progeny of individual rhombomeres form sharply delineated radially oriented compartments, which remained largely intact in late developmental stages.

3. Fundamental morphological units and the development of fiber tracts. In the embryonic central nervous system, the fibers growing out from the clusters of early differentiating neurons pass close to the border zones of the fundamental morphological units, together forming a discrete and stereotyped scaffold of transversely and longitudinally oriented axonal bundles (Wingate and Lumsden, 1996; Kimmel, 1993; Wingate and Lumsden, 1996; Wingate and Lumsden, 1996). Many fiber systems present in the brain of adult vertebrates, including the fasciculus longitudinalis medialis, the stria medullaris, the posterior commissure, and the fasciculus retroflexus, derive directly from the early embryonic axonal scaffold (Wingate and Lumsden, 1996; Puelles, 1995).

4. Segmental expression of developmental regulatory genes. The spectacular finding that the interneuromeric boundaries in the brain correspond with the limits of expression of a number of developmentally significant genes, and that each neuromere can thus be characterized by a specific set of gene expressions (conferring to them a "molecular identity"), has revolutionized neuromorphology. Whereas the longitudinal zonal model, advocated by Herrick (1910), Kuhlenbeck (1973) and many others, has dominated comparative neuroanatomy for almost a century, at present a complementary segmental morphological paradigm for understanding the structural organization of the vertebrate neuraxis, clearly prevails.

5. Molecular underpinning of the concept of Bergquist and Källén. Puelles and Rubenstein (1993) published a model of the mammalian brain, based on a diagrammatic medial view of the brain of a 12.5-day-old mouse embryo, in which the ventricular surface was subdivided by transverse lines into neuromeres, and by a curved horizontal line into a dorsal alar plate and a ventral basal plate. The expression domains of 45 different (putative) developmental regulatory genes were systematically plotted in this model. It appeared that these expressions consistently respected the proposed transverse and longitudinal boundaries. This model was revised in Puelles and Rubenstein
(2003), and once again in Puelles et al. (2007); Figure 8C). The general conclusions drawn from these models were: (1) that the wall of the embryonic brain can be subdivided into a number of "rectangular" domains, each of which is characterized by the expression of a unique combination of developmental regulatory genes, and (2) that these molecularly defined domains represent radially oriented histogenetic units (Puelles and Medina, 2002; Puelles et al., 2004, 2007).

Parallel studies on genes involved functionally at the so-called "isthmic organizer" (review in Echevarria et al., 2003) have revealed special patterning effects restricted to midbrain and rostral hindbrain, including the cerebellum, which partly explains the columnar singularities detected at these levels.

This brief review of the recent literature may suffice to show that in future studies on the structural organization of the vertebrate brainstem, longitudinal zones as well as transverse bands or neuromeres should be taken into consideration, and that the search for radially arranged, fundamental histogenetic units will have to be placed central in such studies.

During the last decades, Luis Puelles and his collaborators have published a number of studies on the relationship between the localization of cell masses and the neuromeric organization in the brainstem of amniotes. Some of these studies were (largely) based on gene expression patterns (Aroca and Puelles, 2005; Puelles et al., 2007; Marín et al., 2008); others were based on quail-chick grafting experiments (Marín and Puelles, 1995; Cambronero and Puelles, 2000), and still others on the immunoreactivity of particular markers (Puelles and Medina, 1994; Puelles and Verney, 1998; Ju et al., 2004). In all of these studies, the results were summarized in tabular fate maps, one of which is reproduced in Figure 9. I used the data accumulated in the publications mentioned for the preparation of a provisional topological chart, in which the various cell masses are projected on a natural plane, viz. the ventricular surface of the brainstem (Figure 10). On the basis of this result, I encourage my friend Luis Puelles and other workers in this field, to present their future results in a topological, rather than in a tabular fashion.

\section{NOTES ON THE MORPHOLOGICAL INTERPRETATION OF TOPOLOGICAL CHARTS OF THE BRAINSTEM}

As expounded in the first section of the present paper, the essence of the topological procedure is that (i) the various cell masses in the brainstem, with the aid of radial vectors, are projected upon the ventricular surface, and that (ii) this surface, with the projections of the cell masses marked upon it, is transformed into a plane. This method has been designed, so that its product does not only yield information about the mutual positional relations of the various cell masses, but also about their presumptive neuroepithelial origin, and therewith about their primary topological position. We have seen that progenitor cells found at the ventricular surface of the brainstem can be divided into a number of "rectangular" fields, and that these fields are related to radially oriented, three-dimensional histogenetic units (Figures 8A,C). Because the postmitotic neurons of the various nuclei migrate radially outward within the confines of their respective histogenetic units (Figure 8C: red arrows), it may be expected that our projection 


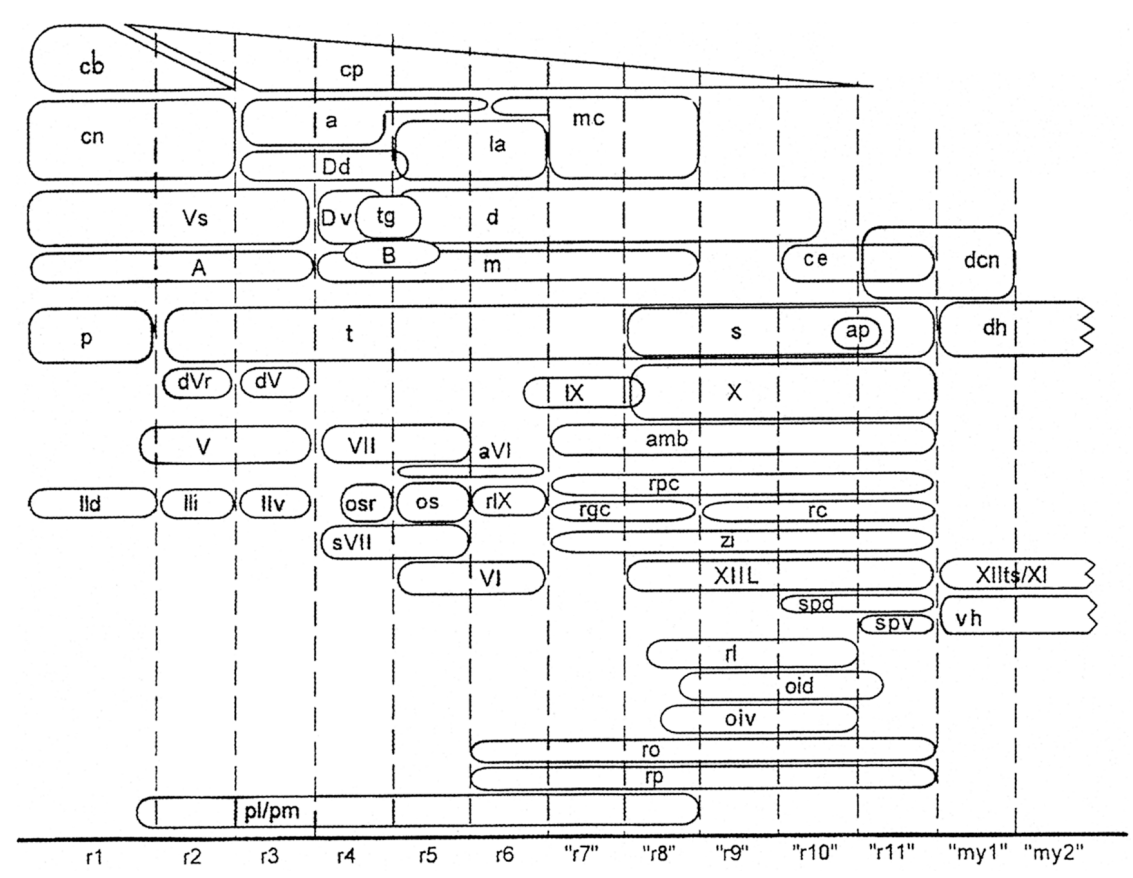

FIGURE 9 | Fate map of avian rhombomeric domains, summarizing data from Marín and Puelles (1995) for rhombomeres r1-r6, and from Cambronero and Puelles (2000) for cryptorhombomeres "r7"-“r11" and cryptomyelomeres "my1" and "my 2." The diagram shows the distribution of nuclei relative to the various segmental boundaries. The relative dorsoventral positions of the columns approximate that in the

embryonic brain. Reproduced with permission from Cambronero and Puelles (2000). method carries these nuclei back to their site of origin. Although this rule holds for many, if not most of the brainstem nuclei, it has some exceptions, the most important of which will be briefly discussed.

1. Populations of immature postmitotic neurons, stemming from different neuromeres and sharing given properties, may unite across the interrhombomeric limits to form bi- or plurisegmental complexes. Thus, the elements forming the abducens nucleus (Figure 11: 1), and those forming the motor trigeminal nucleus, originate both from two different, adjacent neuromeres, and many brainstem nuclei, exemplified here by the nucleus of the fasciculus solitarius (Figure 11:2), are of plurisegmental origin. Moreover, some neuronal populations, such as those forming the catecholaminergic cell groups, constitute highly patterned, plurisegmental and plurizonal complexes (Cambronero and Puelles, 2000; Cambronero and Puelles, 2000). It is thought that such plurisegmental patterns represent a consequence of specific genetic effects shared across neighboring neuromeres (e.g., cell adhesion proteins and various differentiation traits), but nevertheless also imply subtle differences between the analogous populations inhabiting the individual neuromeric units, due to their differential primary segmental identities (i.e., differential constellations of early fate-specifying genes). Such minor differences turn up later in inner circuitry patterns, long-range connectivity patterns and specialized molecular traits related to specialized functional properties, such as the functional anteroposterior specializations observed along the adult cochlear, vestibular, trigeminal and visceral sensory columns.

2. The precursor cells of some brainstem nuclei shift laterally or caudally during ontogeny. As for lateral shift, Windle (1970) found that in human embryos, the neuroblasts, destined to form the branchiomotor nuclei (i.e., the motor nuclei of V, VII, IX, and X) originate close to the median plane of the brainstem, but shift later laterally, to attain their definitive position in the lateral part of the basal plate (Figure 11: 3). Ju et al. (2004), using a molecular definition of the alar-basal boundary and molecular markers, adduced evidence that in avian embryos, the branchiomotor nuclei even invade the rhombencephalic alar plate. The latter finding is hard to reconcile with the situation in adult anamniotes, implying that morphologic versus molecular delineation of the alar-basal limit is presently not consistent, representing a problem that has not yet been resolved. Some authors opted for not identifying either alar or basal territories, classifying structures more vaguely into "dorsal" and "ventral" elements. However, the concept of alar and basal plates, denoting "dorsalized" versus "ventralized" lateral brain wall regions apparently continues to have heuristic value. In the brainstems of all of the 16 different anamniote species investigated by us, the branchiomotor nuclei form a distinct column, occupying the intermediolateral zone of the rhombencephalic basal plate (Figures 4B and 5B). As for caudal shift, it is well known that in mammals, the anlage of the main facial nucleus shifts from rhombomere 5 into rhombomere 6 (Figure 11: 4). 


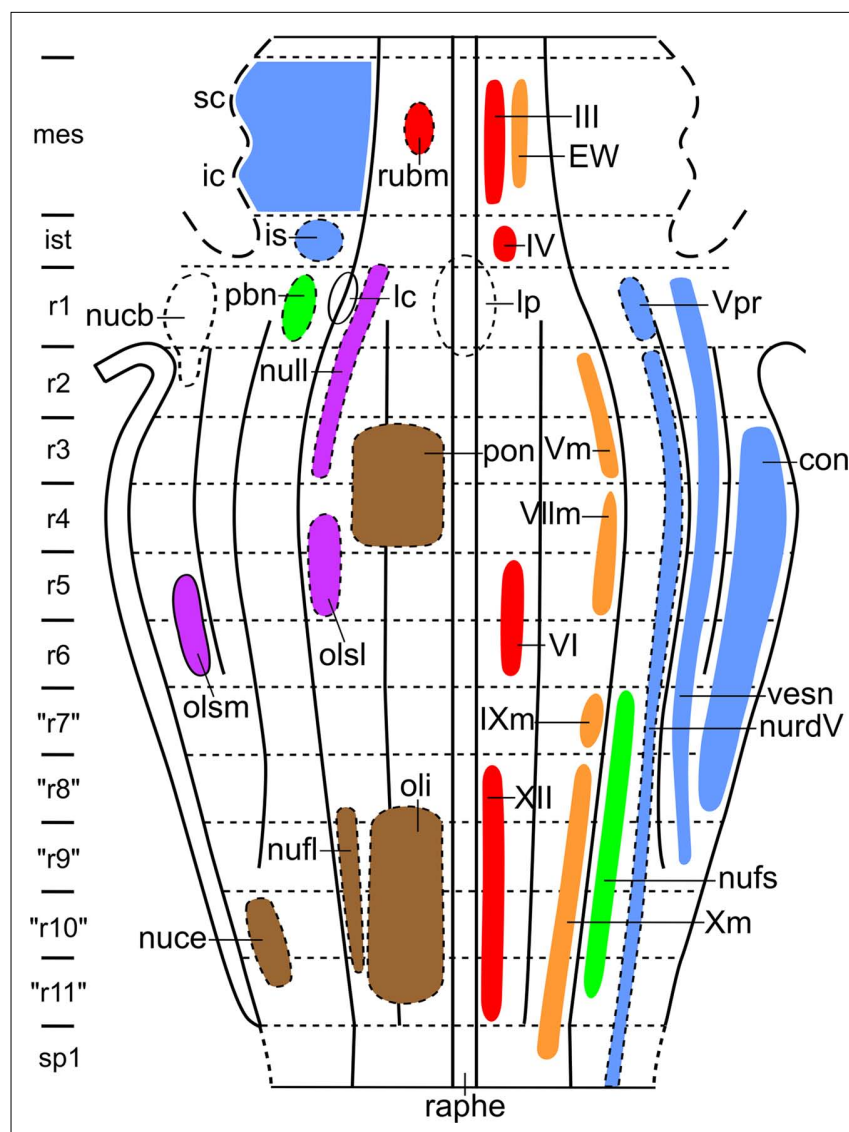

FIGURE 10 | Provisional topological chart of the brainstem of amniotes, showing the zonal and segmental allocation of cell masses, as determined by Puelles and collaborators. In order to avoid crowding, primary sensory and primary motor nuclei are shown to the right, whereas centers of higher order are shown to the left.

3. Two special proliferation zones, the mesencephalic midventral proliferation zone and the rhombic lip, give rise to long tangential migrations in the brainstem. The proliferation zone first mentioned forms a conspicuous component of the mammalian mesencephalic floor plate. Neuroblasts originating from this zone migrate laterally through the marginal zone of the adjacent basal plate. The sheet of cells, resulting from this remarkable tangential migration, represents the dopaminergic, compact part of the substantia nigra (Verney et al., 2001; Figure 11:5). The rhombic lip is a thickened proliferation zone in the rhombencephalic alar plate, situated directly adjacent to the attachment of the membranous roof of the fourth ventricle (Figure 11). Different sectors of the rhombic lip give rise to different structures (see Nieuwenhuys et al., 2008, for references and details). Thus, its most rostral sector provides the neuroblasts, destined to form the cerebellar granular layer. A rostral intermediate part of the rhombic lip gives rise to the cells of the cochlear nuclei, whereas a caudal intermediate portion produces a large stream of tangentially migrating neuroblasts, which invade the basal plate sector of rhombomeres 3 and 4, to form the pontine nuclei (Figure 11: 6). Several streams of tangentially migrating neuroblasts also arise from the caudal sector

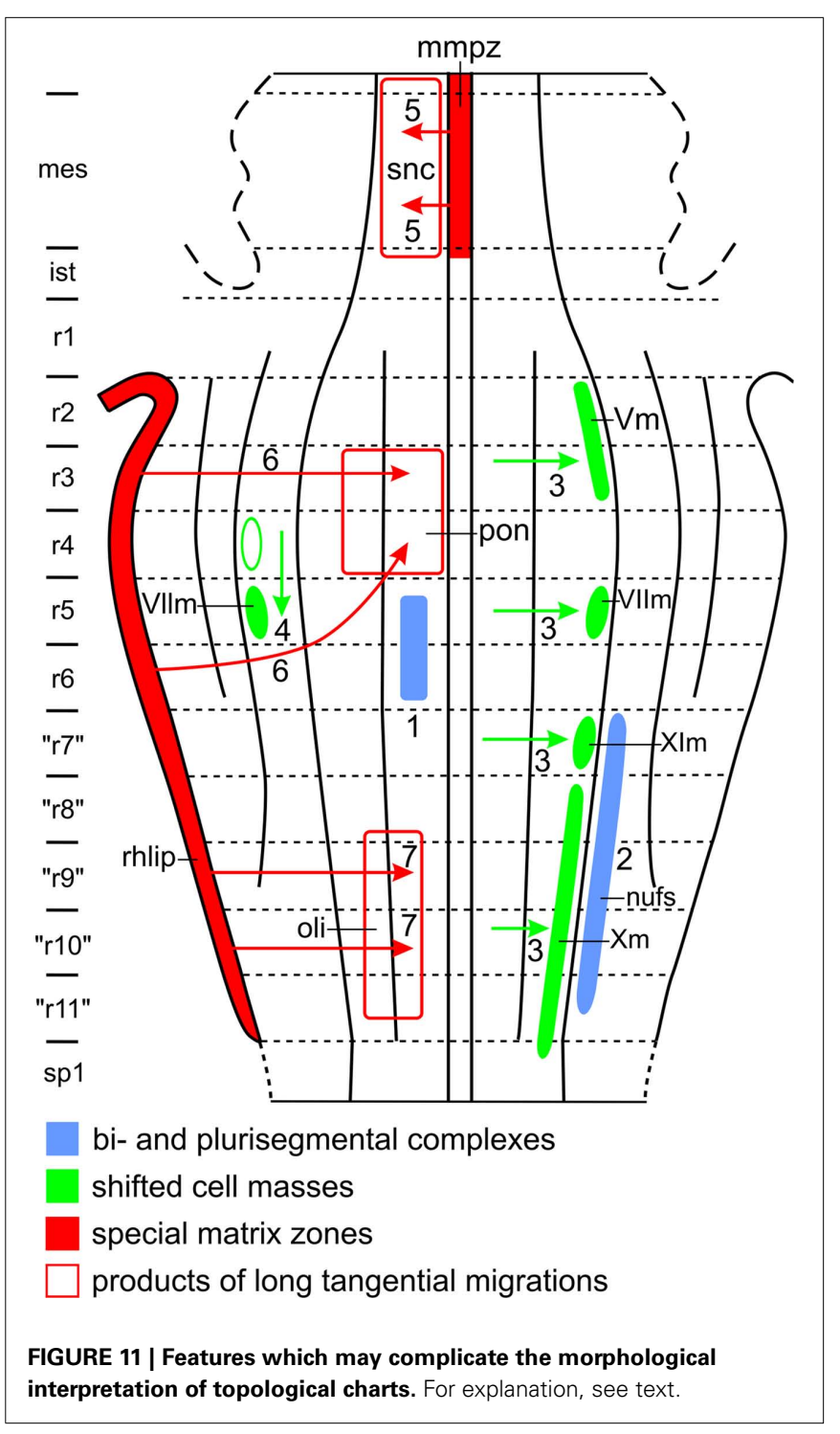

of the rhombic lip. The most prominent of these leads to the formation of the inferior olivary nucleus (Figure 11: 7). Other "precerebellar" nuclei, such as the nucleus cuneatus externus and the nucleus funiculi lateralis (Figure 10), arise from similar, though smaller streams.

The specific purpose of the brief exercitation just presented, is to show that topological maps, derived from the brainstems of adult specimens, have certain important limitations, irrespective of their overall explanatory power. The exceptions discussed, make plain that the topological procedure does not project all cell masses back to their sites of origin and therewith to their primary topological positions. Conversely, it is now clear that the preparation of a topological supermap, showing the genuine primary topological positions of all constituent nuclei in the brainstem of a given species, would require extensive neuroembryological studies involving, inter alia, the expression patterns of numerous developmental regulatory genes and the tracing of all tangential migrations. 


\section{LOOKING BACK, LOOKING FORWARD}

At the time that the present author started this research program, comparative neuroanatomy was dominated by the doctrine that the central nervous system of vertebrates essentially consists of a number of homogeneous longitudinal zones or columns. The brainstem (i. e. the mesencephalon, plus the rhombencephalon, minus the cerebellum) was held to consist of four such zones, which represented, at the same time, structural as well as functional entities. These entities were designated by the noted North American neuroanatomists C. J. Herrick and J. B. Johnston as the somatosensory, viscerosensory, visceromotor, and somatomotor columns. In order to test the validity of this "four-structural/functional-zones" concept, I designed a topological procedure, which rendered it possible to survey the spatial relationships of the cell masses in the brainstem of a given specimen in a single figure. The brainstems of 16 different anamniote species were analyzed with the aid of this procedure. It appeared that the brainstem of anamniotes shows a distinct longitudinal zonal pattern. In the rhombencephalon four morphological zones: ventral, intermedioventral, intermediodorsal, and dorsal could be distinguished, whereas in the mesencephalon three of such zones: medial tegmental, lateral tegmental, and tectal appeared to be present. These morphological zones were found to correspond largely, though not entirely with the functional zones of Herrick and Johnston. This was so, because all of the four morphological zones appeared to contain one or some nuclei, the functional significance of which was not consistent with the functional label of the pertinent zones. In spite of these exceptions, the functionalbrainstem-model has still a certain explanatory significance. Thus, it appeared to be possible to interpret certain brain specializations related to particular behavioral profiles, as local "hypertrophies" of one or two functional columns.

In the mean time, a dramatic paradigm shift occurred in neuromorphology. Different lines of research, and notably gene expression studies, led to the inescapable conclusion that neural segments or neuromeres, which up to that time were generally considered as early and transient embryonic epiphenomena, represent instead fundamental building blocks of the vertebrate neuraxis. In fact, this discovery, which can be positioned in the last decade of the twentieth century, was not entirely new. Forty years earlier, the Swedish neuroembryologists Bengt Källén and Harry Bergquist had already remarked upon the significance of neuromeres. These authors found that longitudinal zones and neuromeres both play a salient role in the development of the central nervous system. They demonstrated that, by intersection of the embryonic longitudinal and transverse zones, rectangular fields of high proliferation develop, whose derivatives in the mantle zone manifest themselves three-dimensionally as radially oriented areas, extending from the ventricular to

\section{REFERENCES}

Addens, J. L. (1933). The motor nuclei and roots of the cranial and first spinal nerves of vertebrates. Part I. Introduction and cyclostomes. $Z$. Anat. Entwicklungsgesch. Gesch. 101, $307-410$. fate in the developing rostral hind-

the meningeal surface of the developing brain. According to Bergquist and Källén, the principal histogenetic events, i. e. proliferation, migration and differentiation, essentially take place within the confines of these areas. On that account, they considered the areas in question as fundamental histogenetic units. Because Bergquist and Källén considered these units as purely morphological entities, to which no functional significance was attributed momentarily, their findings where initially completely neglected. However, during the last two decades, numerous studies, using modern, molecular and neurophysiological techniques, have fully confirmed and substantiated the findings of Bergquist and Källén, indicating that the longitudinal columns have neuromeric subdivisions, whose functional specialties are increasingly becoming apparent in contemporaneous studies (see e. g., Straka et al., 2001, 2006).

The developments just outlined, have led to a complete renewal of the research program discussed. Within the frame of this new program, the following questions will be addressed:

1. What is the exact relationship between the longitudinal zones, as determined by Nieuwenhuys, Bergquist and Källén, and Puelles, respectively?

2. What is the exact number of neuromeres in the brain(stem) of a number of representative anamniotes?

3. Is it true that the brain(stems) of all vertebrates contain a fixed number of fundamental histogenetic units, as Bergquist and Källén surmised?

4. If so, what is the fate (i. e. the specific mode of differentiation) of a number of homologous units within the brain(stems) of some representative anamniotes?

5. Which processes may "disturb" or "complicate" the basic developmental events, occurring within the confines of certain fundamental histogenetic units?

These, and several other related questions will be tackled in the near future by an international research team, consisting of: Agustin González (Complutense, Spain), Michael Hofmann (Bonn, Germany), Ruth Morona (Complutense, Spain), Manuel Pombal (Vigo, Spain), Luis Puelles (Murcia, Spain), Isabel Rodríguez-Moldes (Santiago de Compostela, Spain), Hans Straka (Munich, Germany), Mario Wullimann (Munich, Germany), and myself (Amsterdam, the Netherlands).

\section{ACKNOWLEDGMENTS}

I am grateful to Luis Puelles for many stimulating discussions. Special thanks are due to Ton Put and Wil Maas for help with the illustrations, to Dr. Jenneke Kruisbrink for literature retrieval, and to Suzanne Bakker M Sc for moral support and reference management.

origins for social vocalization in a vertebrate hindbrain-spinal compartment. Science 321, 417-421.

Bergquist, H., and Källén, B. (1954). Notes on the early histogenesis and morphogenesis of the central nervous system in vertebrates. $J$. Comp. Neurol. 100, 627-659. tulated boundaries and differential brain. Brain Res. Brain Res. Rev. 49 179-190.

Bass, A. H., Gilland, E. H., and Baker, R. (2008). Evolutionary
Cambronero, F., and Puelles, L. (2000). Rostrocaudal nuclear relationships in the avian medulla oblongata: a fate map with quail chick chimeras. J. Comp. Neurol. 427, 522-545. 
Echevarria, D., Vieira, C., Gimeno, L., and Martinez, S. (2003). Neuroepithelial secondary organizers and cell fate specification in the developing brain. Brain Res. Brain Res. Rev. 43, 179-191.

Figdor, M. C., and Stern, C. D. (1993). Segmental organization of embryonic diencephalon. Nature 363, 630-634.

Finger, T. E. (1988). Sensorimotor mapping and oropharyngeal reflexes in goldfish, Carassius auratus. Brain Behav. Evol. 31, 17-24.

Fraser, S., Keynes, R., and Lumsden, A. (1990). Segmentation in the chick embryo hindbrain is defined by cell lineage restrictions. Nature 344, 431-435.

Gerlach, J. (1933). Über das Gehirn von Protopterus annectens. Anat. Anz. $75,310-316$

Gerlach, J. (1947). Beitrage zur vergleichenden Morphologie des Selachierhirnes. Anat. Anz. 96, 79-165.

Hanneman, E., Trevarrow, B., Metcalfe, W. K., Kimmel, C. B., and Westerfield, M. (1988). Segmental pattern of development of the hindbrain and spinal cord of the zebrafish embryo. Development 103, 49-58.

Heier, P. (1948). Fundamental principles in the structure of the brain: a study of the brain of Petromyzon fluviatilis. Acta. Anat. Suppl. (Basel) VI, 213.

Heijdra, Y. F., and Nieuwenhuys, R. (1994). Topological analysis of the brainstem of the bowfin, Amia calva. J. Comp. Neurol. 339, 12-26.

Herrick, C. J. (1899). The cranial and first spinal nerves of menidia; a contribution upon the nerve components of the bony fishes. Section 1. Introductory. J. Comp. Neurol. 9, 153-180.

Herrick, C. J. (1910). The morphology of the forebrain in amphibia and reptilia. J. Comp. Neurol. 20, 413-547.

Herrick, C. J. (1913) "Anatomy of the brain," in The Reference Handbook of the Medical Sciences, Vol. 2, (New York: Wood) 274-342.

His, W. (1891). Die Entwickelung des menschlichen Rautenhirns vom Ende des ersten bis zum Beginn des dritten Monats I. Verlängertes Mark. Abh. Math. Phys. Kl. Kgl. Sächs. Ges. Wiss. 17, 1-75.

His, W. (1893). Vorschläge zur Eintheilung des Gehirns. Arch. Anat. Physiol. Anat. Abt. 172-180.

Hjörth, J. T., and Key, B. (2001). Are pioneer axons guided by regulatory gene expression domains in the zebrafish forebrain? Dev. Biol. 229, 271-286.

Holmgren, N., and van der Horst, C. (1925). Contribution to the morphology of the brain of Ceratodus. Acta Zool. 6, 59-165.

Ikenaga, T., Ogura, T., and Finger, T. E. (2009). Vagal gustatory reflex circuits for intraoral food sorting behavior in the goldfish: cellular organization and neurotransmitters. J. Comp. Neurol. 516, 213-225.

Johnston, J. (1902a). The brain of Petromyzon. J. Comp. Neurol. 12, $1-86$.

Johnston, J. (1902b). An attempt to define the primitive functional divisions of the central nervous system. J. Comp. Neurol. 12, 87-106.

Johnston, J. B. (1902c). The brain of Acipenser. Zool. Jahrb. Abt. Anat. Ontogenie Tiere 15, 59-260.

Ju, M. J., Aroca, P., Luo, J., Puelles, L., and Redies, C. (2004). Molecular profiling indicates avian branchiomotor nuclei invade the hindbrain alar plate. Neuroscience 128, 785-796.

Kimmel, C. B. (1993). Patterning the brain of the zebrafish embryo. Annu. Rev. Neurosci. 16, 707-732.

Kremers, J. W., and Nieuwenhuys, R. (1979). Topological analysis of the brain stem of the crossopterygian fish Latimeria chalumnae. J. Comp. Neurol. 187, 613-637.

Kuhlenbeck, H. (1973). Central Nervous System of Vertebrates: Vol. 3 Pt. 2 Overall Morphologic Pattern. Basel: Karger.

Lumsden, A., and Keynes, R. (1989). Segmental patterns of neuronal development in the chick hindbrain. Nature 337, 424-428.

Marín, F., Aroca, P., and Puelles, L. (2008). Hox gene colinear expression in the avian medulla oblongata is correlated with pseudorhombomeric domains. Dev. Biol. 323, 230-247.

Marín, F., and Puelles, L. (1995). Morphological fate of rhombomeres in quail/chick chimeras: a segmental analysis of hindbrain nuclei. Eur. J. Neurosci. 7, 1714-1738.

Meek, J., and Nieuwenhuys, R. (1998). "Holosteans and teleosts," in The Central Nervous System of Verte brates, Vol. 2, eds R. Nieuwenhuys, $\mathrm{H}$. J. ten Donkelaar, and C. Nicholson (Berlin: Springer), 759-937.

Metcalfe, W. K., Mendelson, B., and Kimmel, C. B. (1986). Segmental homologies among reticulospinal neurons in the hindbrain of the zebrafish larva. J. Comp. Neurol. 251 , 147-159.

Nieuwenhuys, R. (1972). Topological analysis of the brain stem of the lamprey Lampetra fluviatilis. J. Comp. Neurol. 145, 165-177.

Nieuwenhuys, R. (1974). Topological analysis of the brain stem: a general introduction. J. Comp. Neurol. 156,
255-276.

Nieuwenhuys, R. (1998a) "Morphogenesis and general structure," in The Central Nervous System of Vertebrates, Vol. 1, eds R. Nieuwenhuys, $\mathrm{H}$. J. ten Donkelaar, and C. Nicholson (Berlin: Springer), 158-228.

Nieuwenhuys, R. (1998b). "Histogenesis," in The Central Nervous System of Vertebrates, Vol. 1, eds R. Nieuwenhuys, H. J. ten Donkelaar, and C. Nicholson (Berlin: Springer) 229-272.

Nieuwenhuys, R. (1998c). "Chondrostean fishes," in The Central Ner vous System of Vertebrates, Vol. 1, eds R. Nieuwenhuys, H. J. ten Donkelaar and C. Nicholson (Berlin: Springer), 701-757.

Nieuwenhuys, R. (1998d). "The coelacanth, Latimeria chalumnae," in The Central Nervous System of Vertebrates, Vol. 2, eds R. Nieuwenhuys, $\mathrm{H}$. J. ten Donkelaar, and C. Nicholson (Berlin: Springer), 1007-1043.

Nieuwenhuys, R., and Nicholson, C. (1998). "Lampreys, Petromyzontidae," in The Central Nervous System of Vertebrates, Vol. 1, eds R. Nieuwenhuys, H. J. ten Donkelaar and C. Nicholson (Berlin: Springer), 397-496.

Nieuwenhuys, R., and Oey, P. L. (1983). Topological analysis of the brainstem of the reedfish, Erpetoichthys calabaricus. J. Comp. Neurol. 213 , 220-232.

Nieuwenhuys, R., and Pouwels, E. (1983). The brain stem of actinopterygian fishes. Fish Neurobiol. 1, 25-87.

Nieuwenhuys, R., Voogd, J., and van Huijzen, C. (2008). The Human Nervous System, 4 th revised edn. Heidelberg: Springer, 967.

Nikundiwe, A. M., and Nieuwenhuys, R. (1983). The cell masses in the brainstem of the South African clawed frog Xenopus laevis: a topographical and topological analysis. J. Comp. Neurol. 213, 199-219.

Opdam, P., and Nieuwenhuys, R (1976). Topological analysis of the brain stem of the axolotl Ambystoma mexicanum. J. Comp. Neurol. 165 285-306.

Opdam, R., Kemali, M., and Nieuwenhuys, R. (1976). Topological analysis of the brain stem of the frogs Rana esculenta and Rana catesbeiana. J. Comp. Neurol. 165, 307-332.

Orr, H. (1887). Contribution to the embryology of the lizard; with especial reference to the central nervous system and some organs of the head; together with observations on the origin of the vertebrates. J. Morphol. 1, 311-372.

Puelles, L. (1995). A segmental morphological paradigm for understanding vertebrate forebrains. Brain Behav. Evol. 46, 319-337.

Puelles, L., Amat, J. A., and Martinezde-la-Torre, M. (1987). Segmentrelated, mosaic neurogenetic pattern in the forebrain and mesencephalon of early chick embryos: I. Topography of AChE-positive neuroblasts up to stage HH18. J. Comp. Neurol. 266, 247-268.

Puelles, L., Martinez-de-la-Torre, M. Paxinos, G., Watson, C., and Martinez, S. (2007). The Chick Brain in Stereotaxic Coordinates. San Diego: Academic Press.

Puelles, L., Martinez, S., Martinez-dela-Torre, M., and Rubenstein, J. L. R. (2004). "Gene maps and related histogenetic domains in the forebrain and midbrain," in The Rat Nervous System, 3rd Edn, ed. G. Paxinos (San Diego: Academic Press), 3-25.

Puelles, L., and Medina, L. (1994). “Development of neurons expressing tyrosine hydroxylase and dopamine in the chicken brain: a comparative segmental analysis," in Phylogeny and Development of Catecholamine Systems in the CNS of Vertebrates, eds W. J. A. J. Smeets, and A. Reiner (Cambridge: Cambridge University Press), 135-181.

Puelles, L., and Medina, L. (2002). Field homology as a way to reconcile genetic and developmental variability with adult homology. Brain Res. Bull. 57, 243-255.

Puelles, L., and Rubenstein, J. L. (1993). Expression patterns of homeobox and other putative regulatory genes in the embryonic mouse forebrain suggest a neuromeric organization. Trends Neurosci. 16, 472-479.

Puelles, L., and Rubenstein, J. L. (2003) Forebrain gene expression domains and the evolving prosomeric model. Trends Neurosci. 26, 469-476.

Puelles, L., and Verney, C. (1998). Early neuromeric distribution of tyrosinehydroxylase-immunoreactive neurons in human embryos. J. Comp. Neurol. 394, 283-308.

Sibbing, F. (1984). Food handling and mastication in the carp (Cyprinus carpio L.). Ph.D. thesis, University of Wageningen, Wageningen.

Smeets, W. J. A. J., and Nieuwenhuys, R. (1976). Topological analysis of the brain stem of the sharks Squalus acanthias and Scyliorhinus canicula. J. Comp. Neurol. 165, 333-368.

Smeets, W. J. A. J., Nieuwenhuys, R., and Roberts, B. L. (1983). The Central Nervous System of Cartilaginous Fishes: Structural and Functional Correlations. Heidelberg: SpringerVerlag. 
Straka, H., Baker, R., and Gilland, E. (2006). Preservation of segmental hindbrain organization in adult frogs. J. Comp. Neurol. 494, 228-245.

Straka, H., Baker, R., and Gillard, E. (2001). Rhombomeric organization of vestibular pathways in larval frogs. J. Comp. Neurol. 437, 42-55.

Thors, F., and Nieuwenhuys, R. (1979). Topological analysis of the brain stem of the lungfish Lepidosiren paradoxa. J. Comp. Neurol. 187, 589-611.

Verney, C., Zecevic, N., and Puelles, L. (2001). Structure of longitudinal brain zones that provide the origin for the substantia nigra and ventral tegmental area in human embryos, as revealed by cytoarchitecture and tyrosine hydroxylase, calretinin, calbindin, and GABA immunoreactions. J. Comp. Neurol. 429, 22-44.

Von Kupfer, K. (1906). "Die Morphogenie des Centralnervensystems," in Handbuch der Vergleichenden und experimentellen Entwicklungsgeschichte der Wirbeltiere, ed. O. Von Hertwig (Jena: Ficher Verlag), $1-272$.
Windle, W. F. (1970). Development of neural elements in human embryos of four to seven weeks gestation. Exp. Neurol. 28(Suppl.) 44-83.

Wingate, R. J., and Lumsden, A. (1996). Persistence of rhombomeric organisation in the postsegmental hindbrain. Development 122, 2143-2152.

Conflict of Interest Statement: The author declares that the research was conducted in the absence of any commercial or financial relationships that could be construed as a potential conflict of interest.
Received: 01 November 2010; accepted: 30 May 2011; published online: 24 June 2011.

Citation: Nieuwenhuys $R$ (2011) The structural, functional, and molecular organization of the brainstem. Front. Neuroanat. 5:33. doi: 10.3389/fnana.2011.00033

Copyright $(\odot 2011$ Nieuwenhuys. This is an open-access article subject to a nonexclusive license between the authors and Frontiers Media SA, which permits use, distribution and reproduction in other forums, provided the original authors and source are credited and other Frontiers conditions are complied with. 